\title{
ON THE OCCURRENCE OF PRIMITIVE ORBITOIDES SPECIES IN GAVROVO - TRIPOLITZA PLATFORM (MAINALON MOUNTAIN, PELOPONNESUS, GREECE)
}

\author{
Zambetakis-Lekkas A. \\ National and Capodistrian University of Athens, Faculty of Geology and Geoenvironment, \\ Department of Historical Geology - Paleontology, Panepistimiopolis, 15784 Zografou, Athens, Greece.
}

\begin{abstract}
Orbitoides genus is considered as a cosmopolitan one, with a worldwide distribution. It characterizes the open shelf sedimentation of late Cretaceous. Therefore, primitive species of the genus have not the same large paleogeographic distribution as the more evolved species. While evolved species of Orbitoides genus are frequently referred in Hellenids, primitive species are reported for the first time in Mainalon Mountain in central Peloponnessus (Zambetakis-Lekkas \& Alexopoulos 2007). In this paper primitive Orbitoides species in the above area are studied and discussed. A new species seems to be identified.
\end{abstract}

Key words: Primitive Orbitoides species, Campanian, Gavrovo-Tripolitza platform, Mainalon Mountain, Peloponnesus, Greece.

\section{Introduction}

Orbitoides genus is considered as a cosmopolitan one, with a worldwide distribution. It characterizes the open shelf sedimentation of late Cretaceous. Therefore, primitive species of the genus have not the same large paleogeographic distribution as the more evolved species.

Primitive Orbitoidids were for the first time described in northern Spain (van Hinte 1966) and western France (Silvestri 1910, van Hinte 1968). Thenceforth, they are found in different localities of the Tethyan belt. While evolved species of Orbitoides genus are frequently referred in Hellenids, primitive species are found for the first time in Mainalon Mountain in central Peloponnessus (Zambetakis-Lekkas \& Alexopoulos 2007).

Primitive species are differentiated from the more evolved ones by the absence or the sporadic presence of lateral chamberlets and by a different chambers arrangement in the juvenile stage of growth. The first "true" Orbitoides species developing lateral chamberlets from both sides of the equatorial plan of chambers, pierced by pillars is Orbitoides tissoti. Both O. tissoti and the younger species have a biconvex outline, due to the well developed lateral chamberlets. Primitive species are recognized by their plan, undulate, or concavo-convex shape of test. The definition of the different species of Orbitoides genus is based on the number and the arrangement of the embryonic and the juvenile chambers in the equatorial layer. In primitive species, contrary to the evolved ones, the equatorial chambers are not disposed in a plan.The undulation starts even from the embryonic and the juvenile stage of growth. This fact obstructs their observation in sections, thus leading to different opinions among several authors regarding the specific or generic attribution of the specimens. The primitive species stratigraphic range is from upper Santonian to lower Campanian, while the evolved ones is from upper Campanian to Maestrichtian. 


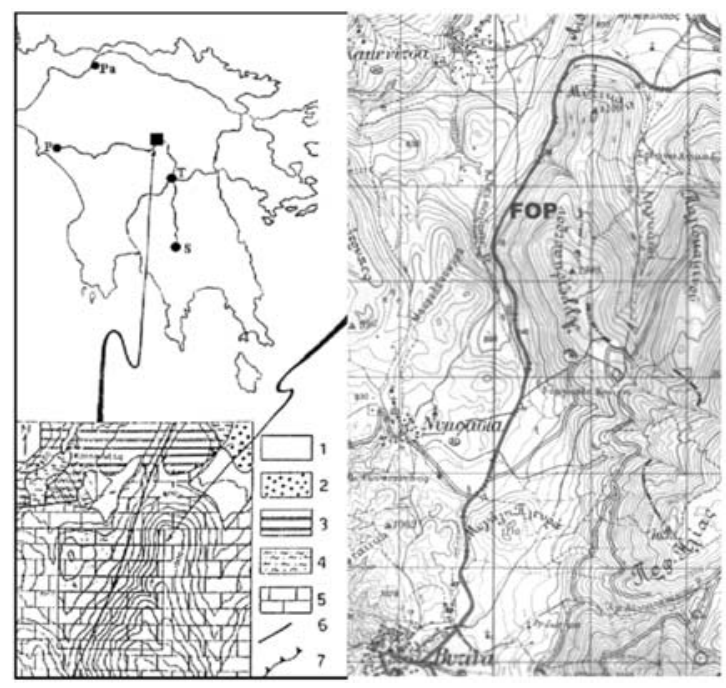

Fig. 1: Localization of the outcrop. Map showing the studied locality. Pa: Patras, P: Pyrgos, T: Tripolis, S: Sparti. 1: Alluvial, 2: Quaternary conglomerates, 3: Upper Cretaceous limestones of the Pindus series, 4: radiolarites, 5: Cretaceous limestones of the Tripolitza series, 6: fault, 7: overthrust (after Zambetakis et al 1988) FOP: Localization of primitive Orbitoides bearing limestones.

\section{Geographical and Geological setting}

Mainalon constitutes the main mountainous ridge of central Peloponnesus. Culminating up to $1867 \mathrm{~m}$ altitude, it consists mainly of Jurassic up to Eocene carbonates of Tripolitza platform, followed by flysh. They are tectonically overlain by Pindus nappe.

Cretaceous carbonates of Tripolitza platform are the most represented in the Mainalon area. Whereas forests, intense tectonization and dolomitization obstruct the observation of continuous stratigraphic sequences, most cretaceous stratigraphic levels are recognized in different sections (ZambetakisLekkas 2006, Zambetakis-Lekkas \& Alexopoulos 2007).

Primitive Orbitoides are found in the vicinity of Vitina, on the road Vitina - Tripolis. (Fig. 1)

\section{Description of the outcrop}

In the western flank of Mainalon mountain, NNE of Vitina village, a carbonate sequence of Aptian-Paleocene age is described along the national road Vitina - Tripolis (Zambetakis-Lekkas \& Alexopoulos 2007). Primitive Orbitoides are found in a faulted block of dark, medium bedded limestones rich in rudist shells. Seventy four thin sections were obtained from seven samples. Primitive Orbitoides are recognized (see specific attribution below). They are associated with rotaliids, echinoids, Cuneolina sp., Dicyclina schlumbergeri, and Calveziconus lecalvezae (Fig. 4/2) dating Campanian age.

\section{Discussion on primitive Orbitoides species}

\subsection{Previous works}

The firstly described primitive Orbitoides species, O. hottingeri (Van Hinte 1966), is characterized 
by a circular test, with parallel sides, flat or folded rather irregularly, saucer-shaped or low conical. The periphery is lobulate and the surface is smooth. According to van Hinte's description, the diameter of the disc varies between 0.8 and $2 \mathrm{~mm}$, with most specimens measuring about $1.5 \mathrm{~mm}$. The thickness of the disc varies between 0.20 and $0.25 \mathrm{~mm}$. As van Hinte remarks, details of the central part of the test can only be studied in vertical and horizontal sections. Therefore, it is fairly impossible to obtain sections perfectly in the median layer due to the fact that the test is rarely flat. This lead to different interpretations of the arrangement of the equatorial chambers especially in the nepionic stage of growth (Neumann 1987; Caus et al. 1996) and as a consequence to a different general and specific attribution of the specimens. The spherical protoconque is followed by a deuteroconque of the same size. The third chamber possesses only one aperture, as well as some of the next chambers. Depending on the position of the aperture the arrangement of the initial chambers may be beserial or spiral. According to Drooger \& Klerk (1985), the biserial or spiral initial stage of $O$. hottingeri reminds that of the microspheric specimens of all later Orbitoides and Omphalocyclus. According to Caus et al. (1996) the adult chambers have the same size as the nepionic ones. O. hottingeri has no lateral chamberlets, but the outer lamella covering the previously exposed shell thickens the lateral wall (Caus et al. 1996). O. hottingeri in the type-locality is included mainly in terrigenous facies and rarely in carbonate platforms. They are lithological related with beds containing planktic foraminifera of $\mathrm{Di}$ carinella asymetrica zone (Caus \& Gomez-Garrido 1989).

O. douvillei was determined as Linderina? douvillei by Silvestri (1910) in Aquitaine (southwestern France). Van Hinte (1968) restudied the topotypes and attributed the species to genus Orbitoides. The author differentiates $O$. douville $i$ from $O$. hottingeri by its $\mathrm{H}$ shaped embryonic apparatus formed by 4 chambers, contrary to the 3 chamber apparatus in $O$. hottingeri. The same author differentiates $O$. tissoti from $O$. douvillei by its biconvex test possessing buttons on the surface, and lateral chamberlets. O. douvillei is characterized by a smooth surface and the absence or rarity of lateral chambers. As Caus et al. (1996) mentioned, "true lateral chambers are not present in O. douvillei, but in some specimens the outer lamella seems to detach itself from the previous ones, leaving a small space, a so-called vacuole, between them". Drooger \& Klerk (1985) mentioned that O.douvillei is the latest Orbitoides without lateral chambers, the embryonic apparatus of the species reminds that of $O$. tissoti but lacks the thickened wall that encloses the H-shaped, 4-chambered apparatus.

O. sanctae- pelagiae was determined as Monolepidorbis sanctae-pelagiae by Astre (1927) in Spanish Pyrenees in campanian marly carbonates. Astre differentiates M. sanctae-pelagiae var. densa without lateral vacuoles and a concavo-convex profile, from $M$. sanctae-pelagiae var vacuolaris possessing lateral vacuoles and a biconvex profile. Hottinger (1966) mentioned the differentiation of M. sanctae-pelagiae by the thickened wall of the embryonic apparatus. The protoconque is bigger than the deuteroconque, while they have the same size in $O$. hottingeri. The same author referred that a gradual transition is observed between the specimens of $M$. sanctae-pelagiae without lateral cavities and M. douvillei with lateral cavities. The author gets together to Astre's attribution of the species to Campanian, putting the Santonian/Campanian limit between the disappearance of dordoniensis (=hottingeri) and the apparition of sanctae pelagiae. Caus et al. (1996) attributed M. sanctae-pelagiae var. densa (Astre 1927) to O. douvillei (Silvestri 1910) of Lower Campanian age (elevata zone) and $M$. sanctae-pelagiae var.vacuolaris to O. tissoti (Sclumberger) of Middle Campanian age (lower part of ventricosa zone. The above authors gave a correlation of Orbitoides lineage zones with planktic foraminiferal zones (Fig. 2).

Summarizing the above, primitive species of Orbitoides genus are characterized by their plan, undulate, 


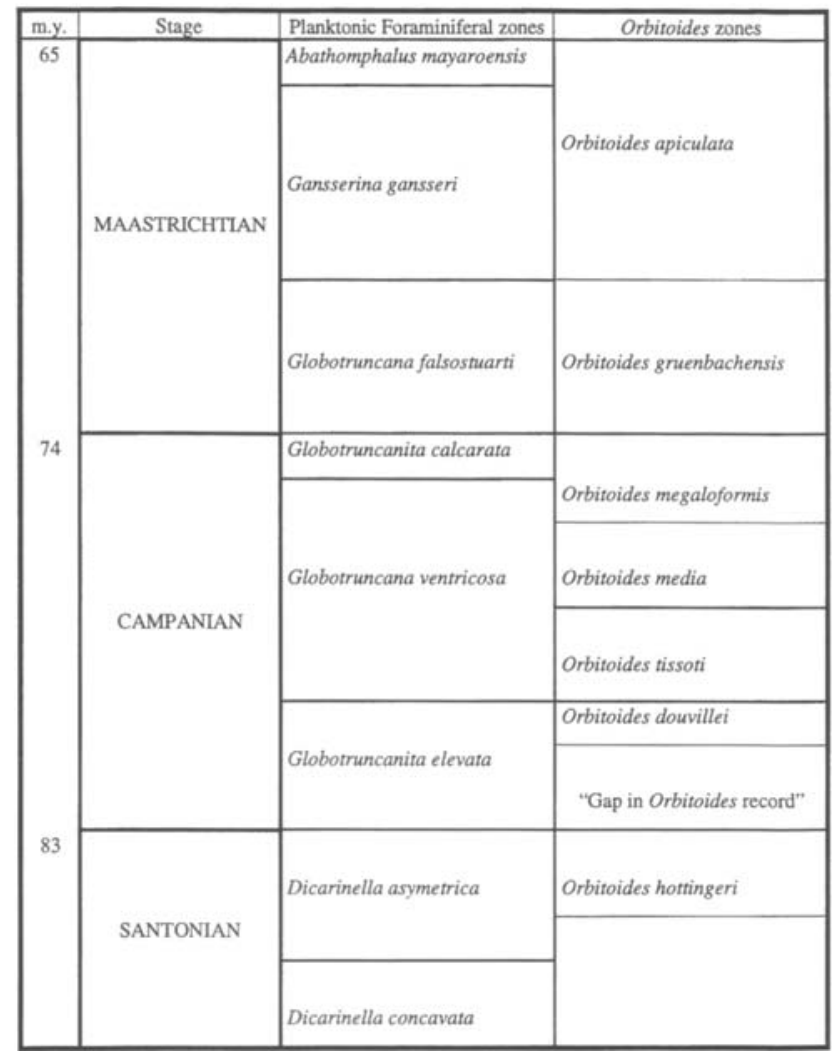

Fig. 2: Correlation of Orbitoides lineage zones with planktic foraminiferal ones (according to Caus et al. 1996).

convex-concave shape of test. They have no or few lateral chamberlets. As Caus at al. (1996) mentioned, they are not true chamberelets but vacuoles formed by a detachment of the outer lamella of the lateral wall. Concerning the embryonic apparatus, according to the concept of different authors, we conclude to the following criteria for the specific determination.

O. hottingeri: 2 chambered embryonic apparatus $(\mathrm{P}=\mathrm{D})$.

O. sanctae-pelagiae: 2 chambered embryonic apparatus $(\mathrm{P}>\mathrm{D})$, with a thickened wall enveloping it (Hottinger 1966).

O. douvillei: 4chambered $\mathrm{H}$ shaped embryonic apparatus, without thickened wall (Drooger \& Klerk 1985)

Apart from O. sanctae pelagiae, primitive Orbitoides species are characterized by the absence of thickened wall enveloping the embryonic apparatus that characterizes the first evolved species, $O$. tissoti. The later possess true lateral chambers, pierced by pillars, causing a biconvex shape of test.

\subsection{Discussion on primitive Orbitoides species in Mainalon area}

The studied material concerns to dark medium to thick bedded limestones, wackestones - pack- 

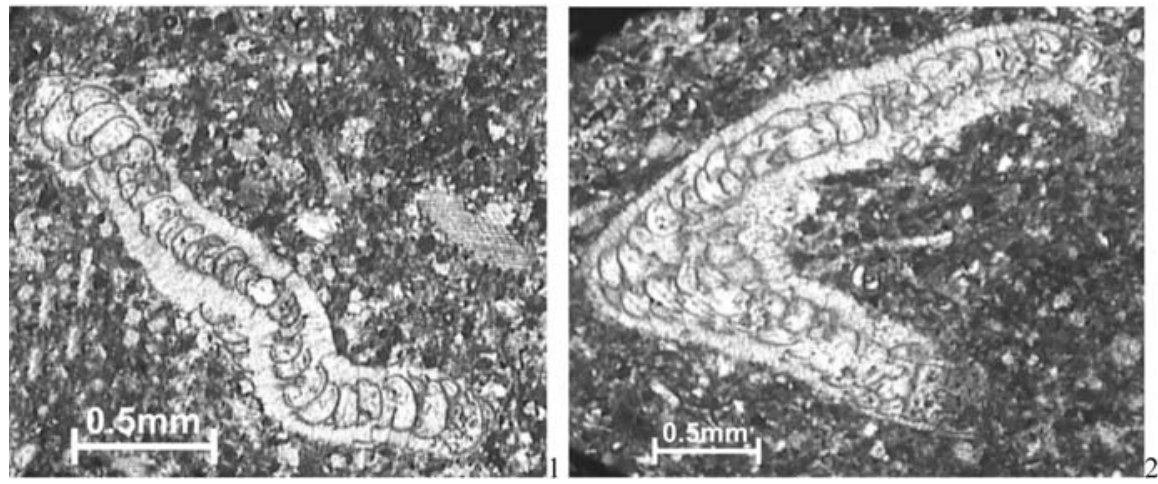

Fig. 3: Primitive Orbitoides species presenting undulate (1) or concavo-convex (2) shape of test.
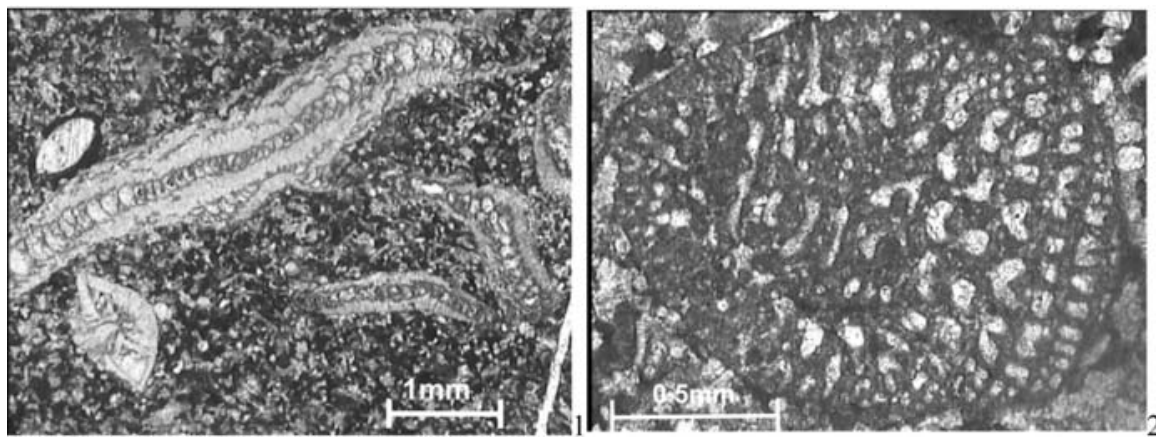

Fig. 4: 1: Primitive Orbitoides species presenting undulate test shape and few lateral chamberles 2: Calveziconus lecalvezae associated with primitive Orbitoides species.

stones. The observed specimens were studied in random thin sections. In these cases it is difficult to obtain oriented sections, necessary to determine the different species. Besides, as mentioned above, the chambers in the median layer of primitive species are not disposed in a plane, as happens in the case of the evolved species of the genus and the undulation starts by the embryonic and juvenile stage of growth. This implies incertitude if a 3 or 2 chambered embryonic apparatus, observed in an axial, or even an equatorial section belongs actually to a specimen with a 2-, 3- or 4chambered embryonic apparatus.

The specimens observed in the studied samples don't possess true lateral chambers, or a biconvex shape of test. They have a plan, undulate or concavo-convex test (Fig. 3). For this reason they are attributed to primitive, pre-tissoti species.

Axial and subaxial sections are mostly obtained. Embryonic and juvenile stage of growth is poorly represented in our sections. So, no measurements were obtained.

An equatorial section (Fig 5/1) presents a 4chambered $\mathrm{H}$ shaped embryonic apparatus, enveloped by a thickened wall. Thickened wall enveloping the embryonic apparatus is observed also in Fig. 5/2, in an oblique subequatorial section. The section cuts 3 of a 4chambered embryonic apparatus. 

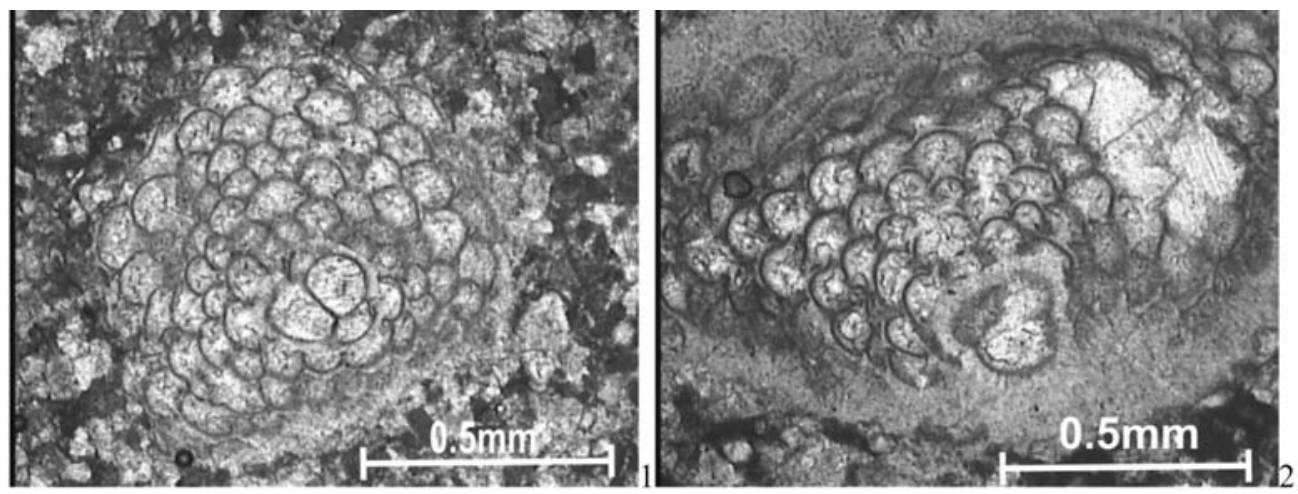

Fig. 5: 1: Equatorial section of specimen with a 4chambered embryonic apparatus enveloped by a thickened wall. 2: Oblique subequatorial section of a specimen possessing an embryonic apparatus enveloped by a thickened wall. The section cuts 3 of the 4 embryonic chambers.
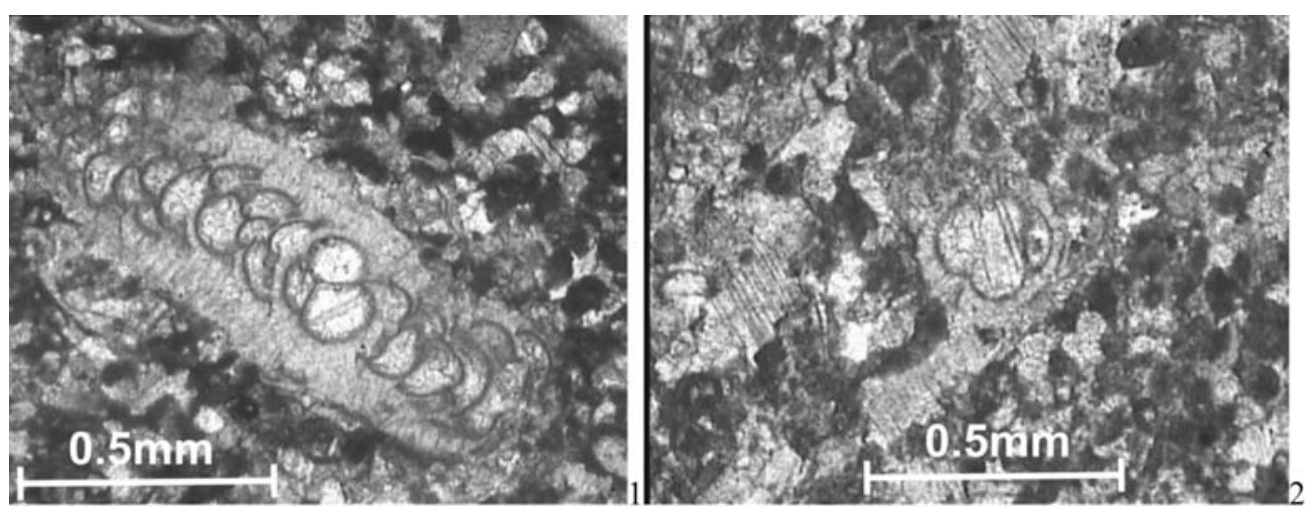

Fig. 6: 1: Axial section cutting 3 of the 4chambered embryonic apparatus, enveloped by a thickened wall.2: Isolated 4chambered embryonic apparatus enveloped by a thickened wall.

An axial section cutting 3 of a 4 chambers of the apparatus enveloped by a thickened wall is presented in Fig 6/1, while Fig 6/2 shows an isolated typical tissoti-embryonic apparatus. Nevertheless no tissoti biconvex specimens, possessing true lateral chambers pierced by pillars were found in the studied material.

Specimens in Fig 7/1,2 show in axial sections a 2chambered embryonic apparatus with $\mathrm{P}>\mathrm{D}$, enveloped by a thickened wall. These specimens could be determined as $O$. sanctae pelagiae according to Hottinger (1966). Nevertheless, the axial sections could also be interpreted as cutting 2 of the 4 chambers of the embryonic apparatus.

The specimens owing a 4-chambered embryonic apparatus differ from $O$. douvillei species, by the thickened wall enveloping it. They could represent a new species, between the douvillei and tissoti evolutionary lineage. More equatorial sections allowing observation and measurements of the features of embryonic apparatus are necessary for the creation of a new species. 

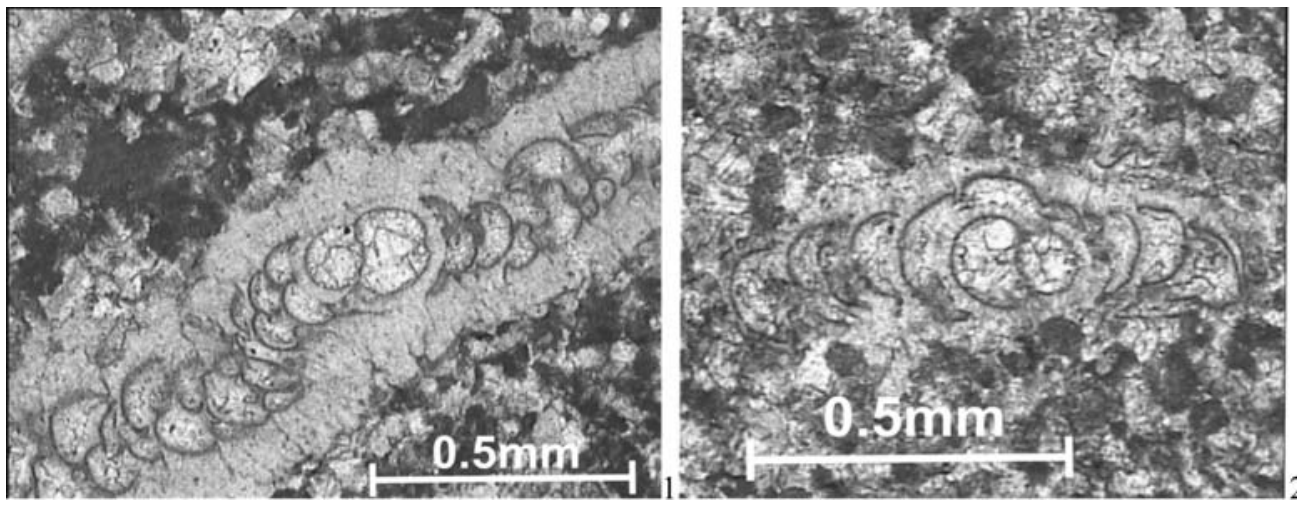

Fig. 7: 1,2: Axial sections showing 2chambered embryonic apparatus with $\mathrm{P}>\mathrm{D}$, enveloped by a thickened wall.

\section{Conclusions}

Primitive Orbitoides species are described for the first time in Greece, in central Peloponnesus, in Mainalon Mountain. They occur in dark medium bedded limestones, wackestones - packstones, rich in rudist tests. They are associated with rotaliids, echinoids, Cuneolina sp., Dicyclina schlumbergeri, and Calveziconus lecalvezae dating Campanian age.

Orbitoides specimens were studied in random sections. They are characterized by a plan, undulate, concavo-convex shape of test. They lack true lateral chambers. Due to the undulation of the test even from the first embryonic and nepionic stage of growth, it is difficult to obtain good equatorial sections, necessary for the specific determination. Specimens showing a 2-chambered embryonic apparatus enveloped by a thickened wall could, with the above reserves, be determined as $O$. sanctae pelagiae. Specimens observed possessing a 4-chambered embryonic apparatus differ from $O$. douvillei by the existence of a thickened wall enveloping the embryonic apparatus. They could represent a new species, between the douvillei and tissoti evolutionary lineage. Nevertheless, more equatorial sections allowing observation and measurements of the features of the embryonic apparatus are necessary for the creation of a new species.

\section{References}

Astre G. 1927. Sur Monolepidorbis, Foraminifère voisin des Linderines et des Orbitoides. Bull. Soc.géol. Fr. sér. 4, v.27, p.387-394.

Caus E., Bernaus J. M. \& Gomez-Garrido A. 1996. Biostratigraphic utility of species of the genus Orbitoides. Journal of Foraminiferal Research, v. 26/2 p. 124-136.

Drooger C.W. \& Klerk de J. C. 1985. The punctuation in the evolution of Orbitoides in the Campanian of South-West France. Utrecht Micropaleontological Bulletins, 33, 132p., 5pl.

Hinte J. E. Van 1966. Orbitoides hottingeri n.sp. from Northern Spain. Proc. Konink. Neder. Akad. Wet. Serie B, vol.69, p.388-402.

Hinte J. E. Van 1968. The Late Cretaceous larger foraminifera Orbitoides douvillei (Silvestri) at its type locality Belvès, SW France. Koninklijke Nederlandse Akademie van Wetenschappen Proceedings, 
ser.B, v.71, p. 359-372.

Hottinger L. 1966. Foraminifères rotaliformes et Orbitoides du Sénonien inférieur pyrénéen. Eclogae geol. Helv. 59/1 pp. 277- 301.

Neumann M. 1987. Le genre Orbitoides. I. Reflexions sur les espèces primitives attribuées à ce genre. Revue de Micropaléontologie, vol. 29/4, pp. 220-261.

Silvestri 1910. Lepidocycline sannoisiane di Antonimina in Calabria.Mem. Accad.Pontif. Romana nuovi Lincei, v.28, p.1-164.

Zambetakis-Lekkas \& Alexopoulos A. 2007. Evolution of a carbonate platform: A case study in the Gavrovo-Tripolitza zone. 25th IAS Meeting of Sedimentology, 2007 Patras, Greece. Field trip A6 p.63-76.

Zambetakis-Lekkas A., Pomoni-Papaioannou F. \& Carotsieris Z. 1988. A Middle Cenomanian-Lower Turonian (?) emergence episode in the Tripolitza subzone (central Peloponnesus, Greece). Rev. De Paléobiologie, v.7/1, pp 129-136. 